\title{
STUDENT PERFORMANCE IN EMERGENCY REMOTE LEARNING AND ASSESSMENT IN SIMULTANEOUS INTERPRETING TRAINING
}

\author{
Alex Krouglov \\ Rezekne Academy of Technologies, Latvia \\ University College London, United Kingdom
}

\begin{abstract}
The paper covers some issues of student performance in Simultaneous Interpreting modules during the emergency remote training in March - June 2020 when many universities around the world had to switch quickly to online synchronous training. Simultaneous Interpreting was chosen for this research since the existing IT platforms for online training are not sufficient in view of the complexity of simultaneous interpreting training which requires special equipment and the availability of two channels of communication. The research explores the main challenges facing trainers and students when they had to move to emergency online teaching and learning and assesses the performance of students in synchronous online simultaneous classes and final examinations or assessments. The study is based on qualitative methods guided by grounded theory and engaged 17 teachers and 24 students at seven universities teaching Simultaneous Interpreting modules. The results of the research showed that the move to emergency remote teaching and learning did not have any significant impact on the performance of students and their assessment in the remaining part of the module. Academic teams came up with a number of innovative solutions for remote teaching, learning and assessment which should be studied further in order to develop effective tools which could be used in synchronous online simultaneous interpreting teaching and learning in the future.
\end{abstract}

Keywords: emergency remote synchronous teaching and learning; simultaneous interpreting; synchronous online examinations.

\section{Introduction}

In response to Covid-19 pandemic in March - June 2020, many universities around the world moved their courses to remote mode of delivery which raised a number of questions about how to support effective online teaching in various disciplines. The transfer of Simultaneous Interpreting (SI) postgraduate modules to online delivery is central in this paper. The subject was chosen for this research because of the technical requirement to have interpreting booths and at least dualchannel communication: one for the incoming presentation or speech in the source language (SL) and another one for the interpretation in the target language (TL) delivered by a student. The synchronous mode is achieved by continuous use of both channels. The existing IT platforms for online teaching used by universities 
Krouglov, 2021. Student Performance in Emergency Remote Learning and Assessment in Simultaneous Interpreting Training

have only one channel which presented a significant challenge for trainers of SI. The present exploratory research aims to assess various approaches at seven universities around the world in providing emergency online synchronous training in SI during the lockdown period of March - June 2020: Comillas Pontifical University, Spain; Ghent University, Belgium; Heriot-Watt University, UK; KU Leuven University, Belgium; London Metropolitan University, UK; Monash University, Australia and Westminster University, UK.

The topic of online or remote teaching and learning remains a dominant theme in higher education worldwide in view of the ongoing pandemic situation. It is, therefore, important to assess the experience of emergency online training in order to develop better approaches for current and future training, especially in subjects where there is a requirement for the use of additional equipment. The framework of the current paper does not allow to cover all major themes explored in our research, e.g., how the transition to online synchronous training was conducted; the format of online classes in SI; what went particularly well and what were the challenges in delivering synchronous online training in SI such as technical difficulties, cognitive strain and lack of social interaction. These and other topics will be presented in a separate publication. This paper will focus on analysing the performance of students during online synchronous training in SI and the provision of online assessments and/or examinations.

The paper will also examine some aspects of emergency transfer to online synchronous mode since trainers had to develop necessary changes to the new remote provision of existing modules in a matter of days or weeks. At the same time, academic teams had to develop some common approaches in order to deliver synchronous training in SI and ensure that the students achieve their module objectives and sit their final SI examinations at the end of the modules.

\section{Literature Review}

The development of ICT influenced the interpreting profession and the introduction of video-mediated interpreting mostly by multi-national organisations. One of the earliest experiments was organised by UNESCO in 1976 linking the headquarters in Paris with a conference centre in Nairobi (Carl \& Braun, 2017). This experiment pushed other organisations to trial online interpreting and a variety of ICT systems. The COVID-19 has dramatically changed how we work, and interpretation was not exempt since many organisations explored further the use remote simultaneous interpreting (RSI) systems since the beginning of the pandemic in 2020 (Chaoui, 2020).

Online synchronous teaching and learning also attracts more and more attention in the $21^{\text {st }}$ century. Some authors thought that synchronous online teaching relies heavily on teachers, that it is good for answering questions and 
troubleshooting while student-centred approach can be developed in asynchronous online teaching which has to become central for learning (Murphy, Rodríguez-Manzanares, \& Barbour, 2011). The statement that synchronous teaching becomes secondary or supporting teaching and learning in asynchronous mode may sound somewhat misleading since in both synchronous and asynchronous teaching and learning teachers have key positions, however their role may change. The role of synchronous training is particularly important in skill-centred disciplines such as Interpreting.

Another area which drew the attention of scholars was around the transfer to online teaching and learning during the pandemic, how the move was managed and what particular requirements for the adaptation of approaches in teaching and learning should be taken into consideration (Boling, Hough, Krinsky, Saleem, \& Stevens, 2012; Koehler \& Mishra, 2009). The authors saw the transformation of routines as the main goal in the transfer to online teaching and learning. A similar situation was witnessed in teaching interpreting where some early synchronous interaction was limited to text messaging, thus mostly considering some basic forms of asynchronous learning and limited forms of synchronous learning (Braun, 2013). Alternatively, some authors considered the use of digital materials in the physical classroom and during self-study periods (Mayor \& Ivars, 2007).

Moser-Mercer examined the development of remote interpreting using the first controlled experiment to evaluate human factors and technical arrangements where factors like "a sense of presence, such as degree of control, immediacy of control, anticipation of events, mode of control and the modifiability of physical environments" were "often compromised in a remote setting" (Moser-Mercer, 2005, p. 79). These findings had a significant impact on the development of the profession and remote teaching where blended approach began to gain more popularity. D'Hayer (2012) argued that technology offered unique benefits when she considered collective learning as a crucial part of public service interpreting. However, the most overarching analysis of online teaching and learning in interpreting was provided by Clifford (2018) when having analysed previous research in the field he examined the nature of online learning in interpreting through different types of interactions, such as learner-content, learner-instructor, and learner-learner.

What is obvious from previous research is that remote courses require significant time for preparation and development or adaptation. However, in contrast to programmes that are planned from the beginning and designed to be online, "emergency remote teaching (ERT) is a temporary shift of instructional delivery to an alternate delivery mode due to crisis circumstances" (Hodges et al., 2020). This definition clearly shows that the emergency remote teaching and learning (ERTL) is an immediate response to external circumstances, and academic staff may not have time to adapt materials or approaches for the online 
Krouglov, 2021. Student Performance in Emergency Remote Learning and Assessment in Simultaneous Interpreting Training

mode. The main objective of the ERTL is to provide access to teaching and learning in a new environment where face-to-face teaching is not possible. The scale and timing of this transfer to the ERTL was perhaps unimaginable in preInternet times. Many universities had to ensure the rapid transfer to online mode, quite often relying on academic staff and their ability to improvise, what is sometimes referred to as "responsive improvisation" (Bryson \& Andres, 2020).

Some authors who analysed synchronous online teaching concluded that it required more concentration from teaching staff and therefore considered more tiring and time-consuming as teachers have to work harder to "decipher" nonverbal and social clues using video links with students (Bryson \& Andres, 2020; Desai, Hart, \& Richards, 2009). Bearing in mind that the switch to ERTL was conducted in a very short period of time, it could have an impact on teaching staff and the quality of modules and courses, accessibility to learning materials and the achievement of learning outcomes. Thus, the current research attempts to analyse what impact the ERTL had on learning and assessment in SI.

\section{Methodology}

The methodology is based on qualitative research methods guided by grounded theory in order to establish whether there was any impact on learning during emergency online teaching and learning in March - June 2020. The current study uses a mixed methods approach where questionnaires are used as an exploratory tool thus enabling us to identify the initial themes followed by interviews with selected teachers and students. At the same time the researcher, who is a trainer of Simultaneous Interpreting and taught remotely during the lockdown period, will aim to maintain an open mind when entering this new area of study of ERTL.

The study was not conducted immediately after the completion of ERTL in SI since it was important to give both academic staff and students more time to assess fully the transfer to online training in an emergency situation. The main part of the research took place in August/September 2020. This timeframe for research was also chosen because many teachers were preparing for the next academic year, and in the majority of cases it was the preparation for the online delivery of SI modules. Participants in the study were lecturers/professionals teaching SI during 2019/20 academic year and postgraduate students in SI modules majoring in Conference Interpreting or Translation and Interpreting at seven universities in Australia, Belgium, Spain and the UK.

In the exploratory part of the research, questionnaires with open questions were used. 17 members of teaching staff participated in the research. There were two members of staff who did not specify the name of their universities in the questionnaires. Overall, 24 students took part in the research and provided 
answers to our questionnaire. It is worth mentioning that both teachers and students participating in the research showed significant interest in the topic and provided comprehensive answers to all open questions included in the survey.

At the initial stage of this research, two anonymous short questionnaires, one for postgraduate students and one for teachers of SI, were designed and first piloted on a group of four students and five teachers in early August 2020. The questionnaire included mostly open questions asking participants to comment on various aspects of online teaching and learning, e.g., about previous experience in remote training and learning, how the switch from face-to-face to online teaching and learning was conducted, what went particularly well and what challenges participants experienced during ERTL. The questions in teachers' questionnaires were slightly modified and included additional questions asking them about previous experience in remote teaching of SI or any other subject, whether there were any variations in student performance during ERTL in comparison with previous face-to-face part of the course. Additionally, there was a question about online assessment and exams and whether they experienced any additional difficulties. This research paper will only address the issue of students' performance as viewed by the teaching staff during ERTL as well as issues related to online assessment and exams.

The qualitative methods used in this research allowed to capture wider issues associated with ERTL in SI and identify some aspects of the best practice in these emerging circumstances. The data received from questionnaires was triangulated with the data obtained during semi-structured interviews with individual students and teachers in participating universities. This approach enabled us to confirm and expand findings based on the answers to open questions in questionnaires and strengthen their validity. Overall, twelve interviews were conducted online: 6 interviews with students and 6 with teachers in participating universities at the end of August/beginning September 2020.

Numerous comments of participants in 37 questionnaires and 12 interviews formed a major part of the data in this study. The findings were split between feedback from students and teachers. All references to quotes from questionnaires will be presented as SQ + ordinal number for students' replies and TQ + number for teachers' replies, while quotes from interviews as SIN + ordinal number for students and TIN + number for teaching staff.

\section{How Do Teachers Perceive Student Performance during ERTL?}

The results of the exploratory questionnaires showed that the predominant theme in teachers' answers was that the performance of their postgraduate students was not affected by the move to ERTL, while some members of staff commented on even positive sides in their SI modules and the progress of students 
Krouglov, 2021. Student Performance in Emergency Remote Learning and Assessment in Simultaneous Interpreting Training

in the new environment. 17 members of staff teaching Simultaneous Interpreting confirmed the following when answering the question on student performance:

- 6 teachers said that the performance was more or less the same as expected;

- 3 members of staff reported that the performance of students was the same or even better;

- $\quad 3$ academics thought that the performance was very well or surprisingly well;

- $\quad$ only 5 teachers reported that there was some negative impact on the overall performance of students, however even these five members of staff confirmed that the overall performance was more or less the same.

Let us consider the comments made by each group of teachers separately in order to identify the reasons for their consideration of student performance during ERTL in March - June 2020. According to our data the majority of SI teachers thought that student performance was similar or unchanged when comparing their performance in pre-ERTL and during ERTL. They strongly believed that their students performed as expected and there were no major differences from faceto-face course in view of their performance, learning and attainment of module outcomes, e.g., TQ8, 5, 6. At the same time, there were a few members of staff who thought that students performed slightly better due to "the comfort and safety" of being in a familiar environment at home (TQ1). There were several teachers who thought that students performed very well during ERTL especially since "the course was filling their day when they could not go out, meet their friends, etc..." (TQ9), as a result, students were "more eager to practise interpreting" (TQ10) and prepare for their classes (TQ2). Several teachers also supported the idea that flexibility and more individual feedback made a positive impact on the overall performance of students in various practical assignments over the period of ERTL (TIN2, 6).

It is interesting, that some other teachers considered the same reason of working from home as a distraction which sometimes even led to interruptions and some loss of concentration during SI tasks. Several teachers mentioned noises outside the house which could have negative impact on the comprehension of the source text and production in the target language (TQ3, TIN1). Obviously, this is very individual and depends on specific circumstances of each student. However, there were other reasons which had a negative impact on student performance. Some teachers thought that a few students felt "more isolated" (TQ4) and had "less support for their peers when they struggled" in performing some tasks (TQ12). Less contact and reduced opportunities to compare their performance with the performance of their peers had some negative impact on the progress the students have made during the ERTL (TIN4, 5). 
It was anticipated that students and teachers would be less happy with the technical arrangement since they had to have two devices in order to listen to a source language speech and produce interpreting into the target language at the same time during their synchronous online classes, however it turned out that although some participants felt some awkwardness about the arrangement, they did not specifically address the issue in their questionnaires or interviews. A couple of teachers reported that the online arrangement was generally more challenging and tiring for both students and teachers (TQ11, 15, TIN1, 3, 4), which confirms the results of previous research reported in the literature review (Bryson \& Andres, 2020; Desai et al., 2009). Some lecturers found it more difficult "to observe and give feedback to each student at every session. It is easier to listen to students when you are on site and students are interpreting from their booths" (TIN1, TQ15). They were of the opinion that you can do more simultaneous interpreting exercises when students and teachers work in the interpreting suite. It was not exactly clear what particular features of the arrangement for synchronous online classes triggered this feedback. The feedback from the majority of students and teachers and interviews did not confirm the view that you can actually do more simultaneous interpreting exercises in face-to-face teaching.

\section{Synchronous Online Examinations}

In this part of the paper, we will consider how the teams of teachers and students managed their examinations or final assessments at the end of the semester. In the exploratory questionnaires to students and teachers we asked similar questions on the issues of assessments and exams: "In your view, how different were online/remote assessments/exams from face-to-face exams/assessments? Did you experience any difficulties or challenges specific to online/remote assessment? Any other comments?” These questions to teachers were slightly modified as they were aimed at eliciting information about the experience of both teachers and students.

It should be noted from the very start, that a couple of teachers and around four students reported that their universities were able to return to campus and conduct face-to-face examinations, while one university opted for non-exam system of assessment. Since the aim of our research was to examine the organisation and provision of synchronous online exams in Simultaneous Interpreting, the interviews were conducted only with students and teachers in universities where online exams took place at the end of the semester.

The data collected from questionnaires and interviews shows a striking difference in the perception of exams at the end of the term. While students were mostly concerned with technical issues, such as stable wi-fi, the ability to 
Krouglov, 2021. Student Performance in Emergency Remote Learning and Assessment in Simultaneous Interpreting Training

coordinate all necessary devices and being able to record the interpretation, teachers were more preoccupied with the process of preparation for the exams and what had to be done to deal with unexpected events. We will analyse these two different approaches further with some examples from questionnaires and interviews.

Students in most universities where the exams were conducted online were worried about various technical issues such as the reliability of their devices or the availability of a stable access to Internet (SQ 1, 3, 7, 8). They identified technical issues as the main difference between online and face-to-face exams. They also thought that their worries about technical issues could have an impact on the level of concentration required in SI (SQ4). One of the students specifically addressed the issue in her questionnaire when she described her experience as "an extra pressure of possible technical failure or internet collapse... I was even worried what if the mailman comes and knocks at the door and I will lose my concentration" (SQ17). These feelings of anxiety and worry were echoed in the majority of comments received from students who apart from technical issues raised the problem of home environment (SQ23, SIN4, 6), which is not always suitable for the examination since most members of families were at home due to lockdown regulations. On the contrary, some teachers thought that the familiar home environment enabled some students to perform better in the exams, e.g., "safety of a familiar space may be less daunting as an exam room with full view of a jury" (TQ2).

The feeling of nervousness was also confirmed by some teachers who expressed their worries about some technical issues and the ability to use effectively new tools which they began to use only during the period of ERLT. Many teams of teachers had to come up with a solution for the way to play the speech and to hear the students' output simultaneously, while using a secure platform. At the same time, they had to record each student's performance. For the purpose of the examination, one team came up with the solution of using Blackboard Collaborate to connect to students, together with a video platform Panopto for speech recording (TQ15, TIN5). There were other solutions in different institutions, however the assessment of technical arrangements was not the aim of this study. The research aimed to analyse challenges the teams had to deal with in preparation for the examination. For example, one teacher expressed her concern about the new tool GoReact which both teachers and students had to use additionally during their exams (TQ3). Others worried about Internet connection and that it would remain stable during synchronous SI examination (TQ14). However, the main concern expressed by teachers was about the increased workload and significant pressure since they had to set all exam papers and make all necessary preparations in a very short period of time while teaching in a completely new environment (TQ1, 4, 7, 17, TIN4, 6). 
It became obvious that academic teams in participating universities spent a lot of time preparing for the exam to ensure smooth running of the online examination. One team developed a step-by-step approach which they presented in a four-page long document split into three parts: before the exam, during the exam and after the exam (TIN1). They even came up with an idea of a "friend" who could press record, someone who could look after the technology during the exam thus enabling the student concentrate on the interpreting task. They also set up an "emergency room" in case there were unforeseen circumstances and students may need some support.

Teams of teachers also ran trials so that students could be familiar with the process and interface (TQ2, 10, 17, TIN1, 5) and this was one more reason for their solid performance in the exam. Another team engaged the students in organising their exam. This collective approach and student agency were extremely useful in assuring that students clearly understood the process and all technical issues which they rehearsed during mock conferences and online classes (TQ9). They also had to deal with other issues, for example some students managed to return to their home countries where they could not get a good connection to the Internet or the chosen platforms could not work in their countries due to various reasons. Academic teams had to come up with a solution on the technical side and remain flexible, e.g., about the timing of the exams (TQ16).

The preparation and the trials conducted before the exams enabled teachers to recreate exam conditions similar or close to what they would have in face-toface situation and contributed to the preparedness of students to deal successfully with the exam tasks in the new remote environment. Most teachers reported that students coped well with the exam speeches, seemed more relaxed during interpreting, and achieved expected or even above expected results. Our findings showed that the thorough preparation and working closely with the students enabled teachers to develop necessary technical and organisational solutions in order to conduct exams effectively in synchronous remote mode.

\section{Some Concluding Remarks}

Synchronous online teaching and learning has enabled the continuation of modules in SI during the lockdown in March - June 2020. Our findings confirmed that academic teams were able to make necessary changes and develop solutions in order to complete the academic year with positive results. Irrespective of all difficulties and uncertainties at the time, students performed well and achieved all their targets for the year. Overall, they were able to complete SI tasks similar to those in face-to-face situations working in an interpreting booth. 
Krouglov, 2021. Student Performance in Emergency Remote Learning and Assessment in Simultaneous Interpreting Training

The analysis of our data showed that our two groups of respondents expressed different concerns with regards to the organisation and running of the exams. While students were worried about technical issues and home environment which could distract them from performing well in the examination, teachers were concerned about the actual organisation of synchronous exams and preparation of speeches for SI. Thorough preparation and close collaboration between students and teachers enabled the teams to develop solutions (both technical and organisational) and conduct examinations in synchronous mode where students generally showed good results.

There were numerous innovations during ERTL which enabled the students to achieve their targets in SI modules, e.g., the introduction of a "friend" in synchronous online examination arrangements, setting up an "emergency room" in case of some technical issues, developing step-by-step procedures, and many others. These developments should be studied further to assess their effectiveness for future blended or synchronous remote teaching and learning in SI and possibly other subjects. The review of the literature confirms that we may anticipate a wider use of remote interpreting in the future, and universities will need to respond by introducing remote interpreting in the curriculum. At the same time, since a vast majority of universities continues to offer online courses, new studies should also address such key issues as student isolation, more support from peers, opportunities for collaborative work and many other relevant topics.

\section{References}

Boling, E. C., Hough, M., Krinsky, H., Saleem, H., \& Stevens, M. (2012). Cutting the distance in distance education: Perspectives on what promotes positive, online learning experiences. Internet and Higher Education, 15(115), 118-126. DOI:10.1016/ j.iheduc.2011.11.006

Braun, S. (2013). Keep your distance? Remote interpreting in legal proceedings: A critical assessment of a growing practice1. Interpreting, 15(2), 200-228. DOI:10.1075/ intp.15.2.03bra

Bryson, J. R. \& Andres, L. (2020). Covid-19 and rapid adoption and improvisation of online teaching: curating resources for extensive versus intensive online learning experiences. Journal of Geography in Higher Education, 44(4), 608-623. DOI:10.1080/ 03098265.2020.1807478

Carl, M. \& Braun, S. (2017). Translation, interpreting and new technologies. In Malmkjaer, K. (Ed.), The Routledge Handbook of Translation Studies and Linguistics (374-390). London: Routledge.

Chaoui, P. (2020). Remote interpretation. UNtoday. Retrieved from https://untoday.org/remoteinterpretation/

Clifford, A. (2018). What does it Take to train Interpreters Online? Communication, Communication and Communication. In Ahrens, B., Hansen-Schirra, S., Krein-Kühle, 
M., Schreiber, M., \& Weinen, U. (Eds.), Translation - Didaktik - Kompetenz: Zur Einführung (169-187). Berlin: Frank \& Timme.

Desai, M., Hart, J., \& Richards, T. (2009). E-learning: Paradigm shift in education. Education, 129(2), 327-334.

D’Hayer, D. (2012). Public Service Interpreting and Translation: Moving Towards a (Virtual) Community of Practice. Meta, 57(1), 235-247. DOI:10.7202/1012751ar

Hodges, C., Moore, S., Lockee, B., Trust, T., \& Bond, A. (2020). The Difference Between Emergency Remote Teaching and Online Learning. EDUCAUSEREVIEW. Retrieved from https://er.educause.edu/articles/2020/3/the-difference-between-emergency-remoteteaching-and-online-learning

Koehler, M. J., \& Mishra, P. (2009). What is technological pedagogical content knowledge? Contemporary Issues in Technology and Teacher Education, 9(1), 60-70.

Mayor, M. B., \& Ivars, A. J. (2007) E-Learning for interpreting. Babel, 53(4), 292-302. DOI:10.1075/babel.53.4.01may

Moser-Mercer, B. (2005). Remote interpreting: The crucial role of presence. Bulletin VALSASLA (Swiss association of applied linguistics) 81, 73-97.

Murphy, E., Rodríguez-Manzanares, M. A., \& Barbour, M. (2011). Asynchronous and synchronous online teaching: Perspectives of Canadian high school distance education teachers. British Journal of Educational Technology, 42(4), 583-591. DOI:10.1111/j.1467-8535.2010. 01112.x 